\title{
The Impact of Titanium Dioxide Type Combined with Coffee Oil Obtained from Coffee Industry Waste on Sunscreen Product Performance
}

\author{
Bruna G. Chiari-Andréo ${ }^{1,2,+}$, Joana Marto ${ }^{3,+}{ }^{+}$, Andreia Ascenso ${ }^{3, *}$, Carlos Carneiro ${ }^{4}$, Laura Rodríguez ${ }^{4}$, \\ Antonio José Guillot $^{4}\left(\mathbb{D}\right.$, Teresa M. Garrigues ${ }^{4}\left(\mathbb{D}\right.$, Helena M. Ribeiro ${ }^{3}\left(\mathbb{D}\right.$, Ana Melero ${ }^{4,+}+{ }^{-}$and Vera Isaac $1, *(\mathbb{D})$ \\ 1 School of Pharmaceutical Sciences, São Paulo State University (UNESP), São Paulo 01049-010, Brazil; \\ bgchiari-andreo@uniara.edu.br \\ 2 Biological and Health Sciences Department, University of Araraquara-Uniara, São Paulo 14801-340, Brazil \\ 3 Research Institute for Medicines (iMed.ULisboa), Faculty of Pharmacy, Universidade de Lisboa, \\ 1649-003 Lisbon, Portugal; jmmarto@ff.ulisboa.pt (J.M.); hribeiro@campus.ul.pt (H.M.R.) \\ 4 Department of Pharmacy and Pharmaceutical Technology and Parasitology, Faculty of Pharmacy, University \\ of Valencia, 46100 Valencia, Spain; carlos.mt.carneiro@gmail.com (C.C.); rodriguez.laura@experior.es (L.R.); \\ antonio.guillot@uv.es (A.J.G.); teresa.garrigues@uv.es (T.M.G.); ana.melero@uv.es (A.M.) \\ * Correspondence: andreiaascenso@ff.ulisboa.pt (A.A.); vera.isaac@unesp.br (V.I.); \\ Tel.: +351-21-794-6400 (A.A.); +55-169-9791-5859 (V.I.) \\ + These authors contributed equally to the research work.
}

Citation: Chiari-Andréo, B.G.; Marto, J.; Ascenso, A.; Carneiro, C.; Rodríguez, L.; Guillot, A.J.; Garrigues, T.M.; Ribeiro, H.M.; Melero, A.; Isaac, V. The Impact of Titanium Dioxide Type Combined with Coffee Oil Obtained from Coffee Industry Waste on Sunscreen Product Performance. Dermato 2021, 1, 2-17. https:// doi.org/10.3390/dermato1010002

Academic Editors: Chang-Seok Lee and Ryan Moseley

Received: 31 March 2021

Accepted: 15 June 2021

Published: 21 June 2021

Publisher's Note: MDPI stays neutral with regard to jurisdictional claims in published maps and institutional affiliations.

Copyright: (c) 2021 by the authors. Licensee MDPI, Basel, Switzerland. This article is an open access article distributed under the terms and conditions of the Creative Commons Attribution (CC BY) license (https:// creativecommons.org/licenses/by/ $4.0 /)$.
Abstract: (1) Background: Titanium dioxide $\left(\mathrm{TiO}_{2}\right)$ consists of three polymorphs, including anatase, rutile and brookite. This work aimed to elucidate the influence of rutile and anatase forms in the performance of sunscreens formulated with green coffee oil (GCO) from coffee beans discarded in the agri-food industry. (2) Methods: $\mathrm{TiO}_{2}$ particles were characterized in terms of size and wettability. The sunscreens formulated with GCO were characterized regarding the droplet size, rheology, texture profile analysis (TPA), in vitro Sun Protection Factor and Water Resistance Retention. Topical delivery and permeation studies were performed to confirm caffeine release and skin penetration. (3) Results: Particle size distributions of rutile and anatase $\mathrm{TiO}_{2}$ particles were similar, however, smaller droplets as well as decreased viscosity and increased thixotropy were obtained for anatase $\mathrm{TiO}_{2}$ and GCO formulation compared to rutile form formulations. Notwithstanding, all formulations exhibited linear viscoelastic behavior. Regarding the TPA, a wide range of mechanical properties improved mainly by GCO rather than $\mathrm{TiO}_{2}$ form has been demonstrated. The influence of $\mathrm{TiO}_{2}$ form on UV protection was better evidenced in absence of GCO. The sunscreen formulations containing GCO presented a favorable topical delivery as confirmed by caffeine release and permeation. (4) Conclusions: Both $\mathrm{TiO}_{2}$ forms combined with GCO provided suitable properties including an effective ultraviolet (UV)-light protection.

Keywords: sunscreen emulsions; titanium dioxide; anatase; rutile; coffee bean waste; caffeine; water resistance retention; sun protection factor

\section{Introduction}

The skin is the largest organ in the human body and represents an essential and dynamic barrier against physical, chemical, and microbial assaults. This barrier is mainly composed by the stratum corneum (SC) layer, which limits the percutaneous penetration of chemicals and microorganisms, and it can resist to the mechanical stress. One of the main physical aggressions to the human skin is the ultraviolet radiation (UV-R), which penetrates the skin layers and triggers a complex process related with morphological and chemical reactions that can damage the cellular DNA. This could lead to photoaging, photo dermatoses and skin cancer, thus it is critical to avoid these undesired effects $[1,2]$. 
Sunscreens have been widely used as the first line of defense against these harmful effects. These formulations contain inorganic or organic filters with the capacity of UVA/B$\mathrm{R}$ absorption, and reflection or scattering [3]. Among the inorganic sunscreens, Titanium dioxide $\left(\mathrm{TiO}_{2}\right)$ is the most employed in the cosmetic and pharmaceutical industry as it provides an effective photoprotection and a moderate skin covering effect related to the nanoscale size of these particles. $\mathrm{TiO}_{2}$ is a white noncombustible and odorless powder with the following physicochemical properties: molecular weight of $79.9 \mathrm{~g} / \mathrm{mol}$, boiling point of $2.972{ }^{\circ} \mathrm{C}$, melting point of $1.843{ }^{\circ} \mathrm{C}$ and relative density of $4.26 \mathrm{~g} / \mathrm{cm}^{3}$ at $25^{\circ} \mathrm{C}$ [4]. The main parameters of these particles that affect their physicochemical properties are the inner structure, size, shape, and surface characteristics, which also influence their toxicity $[5,6]$. The activity of $\mathrm{TiO}_{2}$ particles can be influenced by the surface modification (e.g., coating) [7]. When the surface of $\mathrm{TiO}_{2}$ particles was modified by a grafting-to polymer method based on catalytic chain transfer and thiol-ene click chemistry, the cytotoxicity has decreased [4].

$\mathrm{TiO}_{2}$ particles present three polymorphs-anatase, rutile and brookite [8]. The brookite polymorph is few commercially used, and it is not used in sunscreen formulations. Anatase and rutile are two crystal structures of $\mathrm{TiO}_{2}$, being anatase more chemically reactive [9]. It was reported in literature [4] that the $\mathrm{TiO}_{2}$ particles $(80 / 20$ anatase $/$ rutile at $100 \mu \mathrm{g} / \mathrm{mL}$ and with 3-5 nm) generated 6-fold ROS than rutile form after UV-R (but not at ambient light conditions). These authors suggested that anatase $\mathrm{TiO}_{2}$ had a higher toxic effect than the rutile form. Furthermore, other in vitro and in vivo studies [10] confirmed the preference of rutile over anatase form, especially when the inhalation exposure can occur during the application of the product. In addition to toxicity, the different properties of these two forms might affect the final formulation containing $\mathrm{TiO}_{2}$ in several ways. Nevertheless, few studies have been reported about the influence of $\mathrm{TiO}_{2}$ crystalline forms on the performance of sunscreens, as here proposed.

Additionally, it has been suggested that supplementing sunscreens with active natural compounds may improve the formulation properties and increase their photoprotective potential. A novel substance with this potential, as caffeine from the coffee oil, has been investigated [11-14]. Green coffee oil (GCO) is an oily extract of coffee beans, discarded in the coffee manufacturing process, which can be used as a part of the oily phase of an emulsion (cream). At present, the coffee beans are wasted at tons in agri-food industries since these beans are not useful for the coffee production due to their low palatability. As it has been reported that caffeine enhances the sun protection factor (SPF) [14], the inclusion of GCO in sunscreen formulations could be an alternative and interesting way to use this by-product, thus reducing the industrial waste. Through its UV protective effect observed in human epidemiologic and mice studies, caffeine has inhibited several cellular processes, promoting the elimination of DNA-damaged cells. One mechanism proposed for this effect is the inhibition of ataxia telangiectasia and Rad3-related protein kinase. The results provided by Kawasumi et al. [15] suggest that caffeine, once applied to the skin, could possibly have an inhibitory effect on sunlight-induced skin cancer. GCO also contains other essential oils and natural components that can act as antioxidants and enhance the protecting activity of this main active [16].

In this context, the aim of this study was to elucidate the influence of the polymorphism of $\mathrm{TiO}_{2}$ - rutile and anatase forms - in the performance of sunscreen prototypes formulated with GCO rich in caffeine and extracted from the agri-food industrial waste.

\section{Materials and Methods}

\subsection{Materials}

Titanium dioxide-rutile form (Unipure White LC 987) was a gift from Sensient Technologies Corporation (Milwaukee, WI, USA). Titanium dioxide-anatase form (P-25) was a kind gift from Degussa (Berlin, Germany). Liquid paraffin and propylene glycol were obtained from José Vaz Pereira, S.A. (Lisboa, Portugal). Parabens were acquired from Clariant (São Paulo, Brazil); butyl hydroxytoluene was acquired from Reipu Qingdao International Trade Co., Ltd. (Qingdao, China). Dimethicone was acquired from Dow Corning (Barry, 
UK); ethylhexyl methoxycinnamate was acquired from BASF (Ludwigshafen, Germany); Ceteareth-20, cetearyl alcohol, cetyl palmitate, isopropyl myristate and PEG-75 lanolin, were acquired from Croda (Barcelona, Spain); Mineral oil was acquired from Anastacio (São Paulo, Brazil) and GCO was acquired from a regional coffee cooperative (COOXUPÉ, São Paulo, Brazil). All other reagents were of HPLC grade and used as received. Purified water was obtained by inverse osmosis (Millipore, Elix ${ }^{\circledR} 3$ ).

Caffeine used to prepare the standard solutions was purchased from Sigma (Barcelona, Spain). The solutions were prepared with deionized water (Milli-Q-filtered-HPLC-quality). HPLC grade acetonitrile, hexane and caffeine were obtained from JT Baker (Deventer, The Netherlands).

Porcine skin was obtained from Animal Facilities of the University of Valencia, Spain, after using the porcine donors for surgery training. The Ethical Committee approval of the University of Valencia was obtained under the protocol number H1462978691586.

\subsection{Methods}

\subsubsection{Characterization of Titanium Dioxide $\left(\mathrm{TiO}_{2}\right)$ Powder}

Wettability Measurements

The rutile and anatase contact angles from $\mathrm{TiO}_{2}$ samples were measured by means of the Wilhelmy plate technique using a Krüss Tensiometer K12 (Germany). A rectangle shape substrate coated with a double-side tape $(20 \times 20 \mathrm{~mm})$ was used as plate and the powder was uniformly coated onto its entire surface. The solid samples were hanged perpendicular to the liquid surface. The liquid was placed in a clean glass dish and raised by a motorized platform to contact the powder plate. The platform was raised at the speed of $3 \mathrm{~mm} / \mathrm{min}$ and the submersion distance was $6 \mathrm{~mm}$. The volume used for the contact-angle measurements was approximately $75 \mathrm{~cm}$. All the measurements $(n=6)$ were performed at a controlled temperature $25 \pm 0.5^{\circ} \mathrm{C}$, by flowing water from a circulator system (Haake, Germany). This assay was performed with distilled water (Strom) and with liquid paraffin.

\section{Particle Size Distribution}

Particle size distribution of anatase and rutile $\mathrm{TiO}_{2}$ forms was determined using a Malvern Mastersizer 2000 (Malvern Instruments, Malvern, UK) coupled with a Hydro S accessory. The refractive index used was 1.31 for water and 1.52 for $\mathrm{TiO}_{2}$ (default). For a correct turbidity, about $0.8-1.0 \mathrm{~g}$ of $\mathrm{TiO}_{2}$, corresponding to an obscuration between $10-15 \%$, was added in the sample chamber containing $150 \mathrm{~mL}$ of purified water. The readings were performed under mechanical stirring $(3500 \mathrm{rpm})$ and ultrasonication. Data was expressed in terms of relative distribution of volume of particles in the range of size classes and given as diameter values corresponding to percentiles of 10,50 and $90(n=6)$. The span value of the particle size distribution was calculated by using Equation (1).

$$
\text { Span }=\frac{d(90)-d(10)}{d(50)}
$$

\subsubsection{Characterization of Titanium Oxide Sunscreen Formulations}

Several oil in water $(\mathrm{o} / \mathrm{w})$ emulsions were prepared in order to compare the effect of every polymorph in the absence or presence of GCO.

Two types of oil-in-water $(\mathrm{O} / \mathrm{W})$ emulsions were prepared as controls using a base formulation containing the GCO or a mineral oil at $1.75 \%$ designed as $\mathrm{C}$ or $\mathrm{M}$, respectively. To compare the effect of polymorphs, $3.51 \%$ of anatase $\mathrm{TiO}_{2}$ or $3.51 \%$ rutile $\mathrm{TiO}_{2}$ was added to those controls, producing four emulsions for study as listed in Table 1. 
Table 1. Qualitative and quantitative composition $(\%, w / w)$ of prototype formulations.

\begin{tabular}{|c|c|c|c|c|c|c|}
\hline \multicolumn{7}{|c|}{ Composition (\%) } \\
\hline & AM & AC & $\mathbf{R M}$ & RC & $\mathrm{C}$ & $\mathbf{M}$ \\
\hline Cetearth-20 & 2.63 & 2.63 & 2.63 & 2.63 & 2.63 & 2.63 \\
\hline Cetearyl Alcohol & 5.26 & 5.26 & 5.26 & 5.26 & 5.26 & 5.26 \\
\hline Dimethicone & 0.88 & 0.88 & 0.88 & 0.88 & 0.88 & 0.88 \\
\hline Cetyl Palmitate & 2.63 & 2.63 & 2.63 & 2.63 & 2.63 & 2.63 \\
\hline Isopropryl Myristate & 3.51 & 3.51 & 3.51 & 3.51 & 3.51 & 3.51 \\
\hline BHT & 0.04 & 0.04 & 0.04 & 0.04 & 0.04 & 0.04 \\
\hline Propylparaben & 0.02 & 0.02 & 0.02 & 0.02 & 0.02 & 0.02 \\
\hline Methylparaben & 0.16 & 0.16 & 0.16 & 0.16 & 0.16 & 0.16 \\
\hline Propylene Glycol & 2.63 & 2.63 & 2.63 & 2.63 & 2.63 & 2.63 \\
\hline Peg-75 Lanolin & 1.75 & 1.75 & 1.75 & 1.75 & 1.75 & 1.75 \\
\hline Mineral Oil & 1.75 & - & 1.75 & - & - & 1.75 \\
\hline $\mathrm{TiO}_{2}$ Anatase & 3.51 & 3.51 & - & - & - & - \\
\hline $\mathrm{Tio}_{2}$ V Rutile (T-2000) & - & - & 3.51 & 3.51 & - & - \\
\hline Ethylhexyl Methoxycinnamate & 7.02 & 7.02 & 7.02 & 7.02 & 7.02 & 7.02 \\
\hline Green Coffee Oil & - & 1.75 & - & 1.75 & 1.75 & - \\
\hline Water & 68.20 & 68.20 & 68.20 & 68.20 & 71.71 & 71.71 \\
\hline Total & 100.00 & 100.00 & 100.00 & 100.00 & 100.00 & 100.00 \\
\hline
\end{tabular}

$\mathrm{C}$ and $\mathrm{M}$ : controls using a base formulation containing the $\mathrm{GCO}$ or a mineral oil, respectively. $\mathrm{AC}, \mathrm{AM}$ : sunscreens containing anatase polymorph of $\mathrm{TiO}_{2}$ and formulated a GCO or a mineral oil, respectively. RC, RM: sunscreens containing rutile polymorph of $\mathrm{TiO}_{2}$ and formulated with $\mathrm{GCO}$ or a mineral oil, respectively.

\section{Droplet Size Distribution}

The droplet size distribution of $\mathrm{TiO}_{2}$ sunscreen formulations was determined as described above using Malvern Mastersizer 2000. The refractive index used was 1.31 for water and 1.52 for emulsions (default). For a correct turbidity, about $0.5-1.0 \mathrm{~g}$ of emulsions was added in the sample chamber containing $150 \mathrm{~mL}$ of purified water. The readings were performed under mechanical stirring (700 rpm).

\section{Structure Analysis}

The rheological properties of the $\mathrm{TiO}_{2}$ sunscreen formulations were examined using rotational viscometer and oscillation tests. All tests were performed on samples of about $1 \mathrm{~g}$ at $32.0 \pm 0.5^{\circ} \mathrm{C}(n=3)$.

\section{(A) Dynamic viscosity—Flow curves}

Shear rate versus shear stress measurements were performed using a HAAKE RS-1 Rheometer, equipped with automatic gap setting (Thermo Scientific ${ }^{\mathrm{TM}}$, Waltham, MA, USA). Rotational viscosity was determined using C $35 \mathrm{~mm}$ cone geometry, with an angle of $2^{\circ}$. Dynamic or shear viscosity measurements were carried out by rotational shear experiments between 1 and $1000 \mathrm{~Pa}$ of shear stress on a logarithmic increment to investigate the effect of each formulation on the viscosity. Flow curves were generated by ramping the shear rate from 0 to $100 \mathrm{~s}^{-1}$ in $120 \mathrm{~s}$ (ascent curve), and then, from 100 to $0 \mathrm{~s}^{-1}$ in $120 \mathrm{~s}$ (descent curve) and recording the shear stress throughout $[17,18]$.

(B) Oscillation measurements

Oscillatory measurements were performed to investigate the behavior of the formulations at small deformations. The small amplitude dynamic tests provide information about the linear viscoelastic behavior of the materials $[19,20]$. Viscoelastic experiments were obtained by exposing the samples to a forced oscillation deformation. Prior to the oscillation tests, the stress sweep test was conducted at a frequency of $1 \mathrm{~Hz}$, with a shear stress range from 0 to $50 \mathrm{~Pa}$, while the frequency sweep test was performed over a frequency range from 0.1 to $50 \mathrm{~Hz}$, at a shear stress of $1.5 \mathrm{~Pa}$ [21].

The creep and recovery tests were carried out with a shear stress of $1.5 \mathrm{~Pa}$, allowing $120 \mathrm{~s}$ for creep and other $120 \mathrm{~s}$ for relaxation. 
Texture Profile Analysis (TPA)

A Texture Analyzer TA. XT Plus (Stable Micro Systems Ltd., Surrey, UK) was used to examine the textural characteristics (hardness, elasticity, compressibility, adhesiveness, and cohesiveness) of the $\mathrm{TiO}_{2}$ sunscreen formulations. The TPA mode was carried out using an analytical probe $(\mathrm{P} / 10,10 \mathrm{~mm}$ Delrin) which was twice depressed into the sample at a defined rate $(5 \mathrm{~mm} / \mathrm{s})$ to a desired depth $(15 \mathrm{~mm})$, allowing $15 \mathrm{~s}$ of delay between consecutive compressions. The samples were placed into cylindrical tubes with the same dimensions (at a fixed height). Six replicates were measured at $25^{\circ} \mathrm{C}$ for each formulation. Data collection was performed using the Texture Exponent 3.0.5.0 software package of the instrument.

\section{In Vitro Studies of Sun Protection Factor and Water Resistance Retention}

The SPF of the four sunscreen prototypes (AC, AM, RC and RM) was assessed by using the Optometrics SPF-290S Analyzer. The samples were prepared by spreading $110 \mathrm{mg}$ of each formulation over a Transpore ${ }^{\circledR}$ tape $(70.7 \times 70.7 \mathrm{~mm})$ to obtain a film of $2 \mathrm{mg} / \mathrm{cm}^{2}$, as specified by the European legislation [22]. After $15 \mathrm{~min}$, each sample was exposed to a Xenon arc solar simulator, and the analyzer performed scans in 6 different spots on the Transpore ${ }^{\circledR}$ tape substrate. Each scan takes a transmittance $(\mathrm{T})$ measurement every $2 \mathrm{~nm}$ from a wavelength ranging from 290 to $400 \mathrm{~nm}$. The Monochromatic Protection Factor (MPF) is determined for the selected wavelengths by Equation (2). The SPF value is calculated by Equation (3).

$$
\begin{gathered}
\mathrm{MPF}=1 / \mathrm{T} \\
\mathrm{SPF}=\frac{\sum_{290}^{400} \mathrm{E} \lambda \cdot \mathrm{B} \lambda}{\sum_{290}^{400} \frac{\mathrm{E} \lambda}{\mathrm{MPF} \lambda}}
\end{gathered}
$$

where $\mathrm{E}$ is the spectral irradiance of terrestrial sunlight under controlled conditions and $\mathrm{B}$ is the Erythemal Effectiveness [23].

The water resistance of sunscreens was measured by using an in vitro bath system (at $29 \pm 2{ }^{\circ} \mathrm{C}$ ) and washed away by the water flow $(150 \mathrm{rpm})$ during $20 \mathrm{~min}$. The samples were allowed to air dry for $15 \mathrm{~min}$ and SPF was measured again. The percentage of water resistance retention (\%WRR) of the sunscreens was calculated according to Equation (4).

$$
\% \mathrm{WRR}=\frac{[\text { SPFwet }-1]}{[\text { SPFdry }-1]} \times 100
$$

where SPFdry and SPFwet are the SPFs before and after water immersion, respectively [24,25]. After $15 \mathrm{~min}$, each sample was exposed to a Xenon arc solar simulator, and the analyzer performed scans in 6 different spots on the Transpore ${ }^{\circledR}$ tape substrate. Each scan takes a transmittance (T) measurement every $2 \mathrm{~nm}$ from a wavelength ranging from 290 to $400 \mathrm{~nm}$.

This method requires a sun protection factor to be measured following a defined water immersion procedure. For a product be considered water resistant, the value for the $90 \%$ lower unilateral confidence limit [mean \%WRR $-\mathrm{d}$ ] has to be higher than or equal to $50 \%$ [24].

Topical Delivery Studies

\section{(A) In Vitro Caffeine Release}

The release of caffeine from the prototypes containing GCO was evaluated using the Franz diffusion cell system. The receiver compartment was filled with $12 \mathrm{~mL}$ phosphate buffer $1.15 \mathrm{mM} \mathrm{pH}$ 5.5. This buffer roughly reproduces the characteristics of $\mathrm{pH}$ and osmotic pressure of the skin surface, according to the criteria of the Organization for Economic Cooperation and Development [26].

Additionally, mildly acidic medium allowed maintaining the sink conditions throughout the experimental period as caffeine is more soluble in this $\mathrm{pH}$ in its ionized form due 
to alkaline properties. A synthetic standard-grade RC dialysis membrane cellulose tubing (Spectrum ${ }^{\mathrm{TM}}$ ) with the diffusion area of the donor compartment $\left(1.76 \mathrm{~cm}^{2}\right)$ was used. The system was equilibrated for $20 \mathrm{~min}$ to achieve around $32{ }^{\circ} \mathrm{C}$ (the physiological temperature of the skin surface). The formulation under study was placed in the donor compartment $(1 \mathrm{~g})$ covering the diffusion surface.

Sampling was performed from the receptor compartment at predetermined time points and the caffeine content was analyzed by a previously validated HPLC method adapted from literature $[27,28]$. Briefly, the equipment consisted of an isocratic pump Waters 1515, automatic injector Perkin-Elmer Series 200, UV detector Perkin-Elmer and Chromera ${ }^{\circledR}$ software (Waters Co. Barcelona, Spain). The stationary phase was a Kromasil RP-18 column, $150 \times 4.6 \mathrm{~mm}$ ID with particle size of $5 \mu \mathrm{m}$ (Análisis Vínicos, Tomelloso, Spain). The mobile phase consisted of water ( $\mathrm{pH} 4.0)$ and acetonitrile (80:20, V/V). Before use, it was filtered through a $0.45 \mu \mathrm{m}$ nylon membrane filter (Análisis Vínicos, Tomelloso, Spain) and sonicated for $5 \mathrm{~min}$. The analysis was carried out under isocratic conditions using a flow rate of $1.5 \mathrm{~mL} / \mathrm{min}$ and an injection volume of $50 \mu \mathrm{L}$. Chromatograms were recorded at $270 \mathrm{~nm}$ with a run time of $4 \mathrm{~min}$.

The percentage of the caffeine dose diffused at after each sampling point was plotted versus the sampling times. A non-linear regression of the results was applied, as proposed by Peppas [29]. In this model, Equation (5) was fitted to data.

$$
\frac{Q_{t}}{Q_{\text {inf }}}=\mathrm{K}_{\mathrm{d}} \cdot t^{n}
$$

In which, Qt / Qinf represents the accumulated percentage of caffeine released at time $t$ (expressed in hours), Kd represents the release constant and $n$ is an exponent that depends on different phenomena involved in the release process, such as erosion, distribution or swelling of the excipient. The exponent approaches 0.5 when the release is controlled by the excipient. To perform this nonlinear fitting, Excel@ 2021 was used.

\section{(B) In vitro caffeine permeability}

Porcine ear skin was obtained from the animal facilities and prepared for freeze-storage within the four subsequent hours after excision. The full thickness skin was separated from the cartilage by gentle pulling with forceps after scalpel excision and stored wrapped into foil at $-20^{\circ} \mathrm{C}$ for a maximum of three months. After thawed, this skin was placed between the donor and receptor compartments of the Franz diffusion cells under stirring (500 rpm) at $32{ }^{\circ} \mathrm{C}$. The rest of the experiment followed the same conditions as described for the release studies. A solution of caffeine at $25 \mathrm{mg} / \mathrm{mL}$ in water and pure GCO were also used as controls.

After HPLC analysis, the cumulative amounts of permeated caffeine from tested formulations and controls (GCO and caffeine solution) were plotted versus the sampling times, and the permeability parameters-flow, permeability coefficient and lag time-were calculated by applying a minimal least square linear regression of the steady state points, using Excel@ 2021.

\section{Statistical Analysis}

One-way ANOVA $(\alpha=0.05)$ and Tuckey test were performed when more than two groups were compared. Student $t$-test $(\alpha=0.05)$ was used for comparison of only two groups. Statistical analysis of parameters allows comparing the prototypes to determine: the influence of anatase and rutile $\mathrm{TiO}_{2}$ forms ( $\mathrm{AM}$ vs $\mathrm{RM}$ and $\mathrm{AC}$ vs RC); the influence of presence / absence of $\mathrm{TiO}_{2}$ (AM vs $\mathrm{M}$ and $\mathrm{AC}$ vs $\mathrm{C}$ for anatase; $\mathrm{RC}$ vs $\mathrm{C}$ and $\mathrm{RM}$ vs $\mathrm{M}$ for rutile); and the influence of oil type (AM vs $A C$ and $R M$ vs RC; $C$ vs $M$ controls). For the statistical analysis, the SPSS@ 26 was used. 


\section{Results and Discussion}

\subsection{Characterization of $\mathrm{TiO}_{2}$ Powder}

$\mathrm{TiO}_{2}$ has been effectively used in cosmetic sunscreens for a long time [30]. Its safe use as an UV-filter at a maximum concentration of $25 \%$ and particle size higher than $100 \mathrm{~nm}$ in cosmetic products has already been recognized by the Scientific Committee on Consumer Safety [31]. It is especially recommended for individuals with a high tendency for skin irritation [5]. Moreover, $\mathrm{TiO}_{2}$ is essential for manufacturing sunscreens with a high SPF [5] and its properties guarantee that formulations are "lighter" and can be spread more regularly on the skin, thus improving the UV protection [32].

$\mathrm{TiO}_{2}$ appears in two natural forms-anatase and rutile. It is generally assumed that rutile, the most stable polymorph, is also the most effective one due to a larger absorption of UV-R. Additionally, its hydrophobic nature allows a more durable water resistance, which is quite important for sunscreen formulation.

Wettability measurements

The wettability properties of solid particles determine the water resistance performance of sunscreens. Therefore, oil-wet particles with higher angles in contact with water would be desirable.

Anatase $\mathrm{TiO}_{2}$ presented a contact angle with water of $70.24 \pm 5.74^{\circ}$. The contact angle for rutile was higher $\left(105.60 \pm 1.17^{\circ}\right)$ due to its higher hydrophobicity. There was a statistically significant difference between these input groups $(p<0.05)$. Both $\mathrm{TiO}_{2}$ forms presented angles lower than $20^{\circ}$ when measured with paraffin.

According to these results, the rutile form would be more suitable for water resistance sunscreens.

\section{Particle size distribution}

According to Table 2, there were significant differences in particle size which was much higher in rutile form than anatase form with span values of $3821 \mathrm{~nm}$ and $595 \mathrm{~nm}$, respectively. In contrary, Teruhisa et al. [33] reported that average sizes of the anatase and rutile elementary particles (Degussa ${ }^{\circledR}, \mathrm{P}-25$ ) determined by transmission electron microscopy were 85 and $25 \mathrm{~nm}$, respectively. Thus, higher Span values here recorded could be associated with an aggregation phenomenon of both forms of $\mathrm{TiO}_{2}$ in the aqueous medium where measurements were performed. Nevertheless, as this dispersing medium is different from that in the sunscreen formulations produced here, the $\mathrm{TiO}_{2}$ particles may be dispersed at a finer state in these formulations. In fact, it is prudent to assume this characterization assay could be quite challenging.

Table 2. Particle size distribution with different forms of $\mathrm{TiO}_{2}$ (results expressed as mean $\pm \mathrm{SD}$, $n=3)$.

\begin{tabular}{ccccc}
\hline \multicolumn{5}{c}{ Particle Size Distribution $(\boldsymbol{\mu m})$} \\
\hline Samples of $\mathbf{T i O}_{\mathbf{2}}$ & Span & $\boldsymbol{d} \mathbf{( 0 . 1 )}$ & $\boldsymbol{d} \mathbf{( 0 . 5 )}$ & $\boldsymbol{d} \mathbf{( 0 . 9 )}$ \\
\hline Anatase form & $0.595 \pm 0.001$ & $0.136 \pm 0.001$ & $0.179 \pm 0.001$ & $0.242 \pm 0.001$ \\
Rutile form & $3.821 \pm 2.471$ & $1.146 \pm 0.001$ & $0.210 \pm 0.001$ & $1.952 \pm 0.527$ \\
\hline
\end{tabular}

\subsection{Characterization of $\mathrm{TiO}_{2}$ Sunscreen Formulations}

\section{Droplet Size Distribution}

In this assay, the influence of the $\mathrm{TiO}_{2}$ polymorph on emulsions' droplet size was evaluated. Theoretically, smaller droplets contribute to obtain a more stable emulsion, as observed in the prototype $\mathrm{AC}$ containing anatase $\mathrm{TiO}_{2}$ and GCO. In this case, a significant percentage of droplets exhibited a size ranging from 0.1 to $0.5 \mu \mathrm{m}$ differing from the other prototypes (including rutile $\mathrm{TiO}_{2}$ formulations) about $10 \mu \mathrm{m}$ (Figure 1). The peaks around $10 \mu \mathrm{m}$ for all prototypes except AC could be due to the presence of aggregates, as mentioned before. It can be also observed that a lower droplet size was obtained in the formulation 
containing P25 and green coffee oil which could be explained by the difference in particle size obtained for each form. Therefore, both $\mathrm{TiO}_{2}$ form (especially AC vs RC) and oil type (mineral or green coffee oil in each prototype) affected the droplet size distribution of these emulsions. As previously outlined by Marto et al. (2016) [32], there are several factors that can explain these results, namely the wettability of the solid particles (anatase and rutile) at the oil-water interface also related to their solubility.

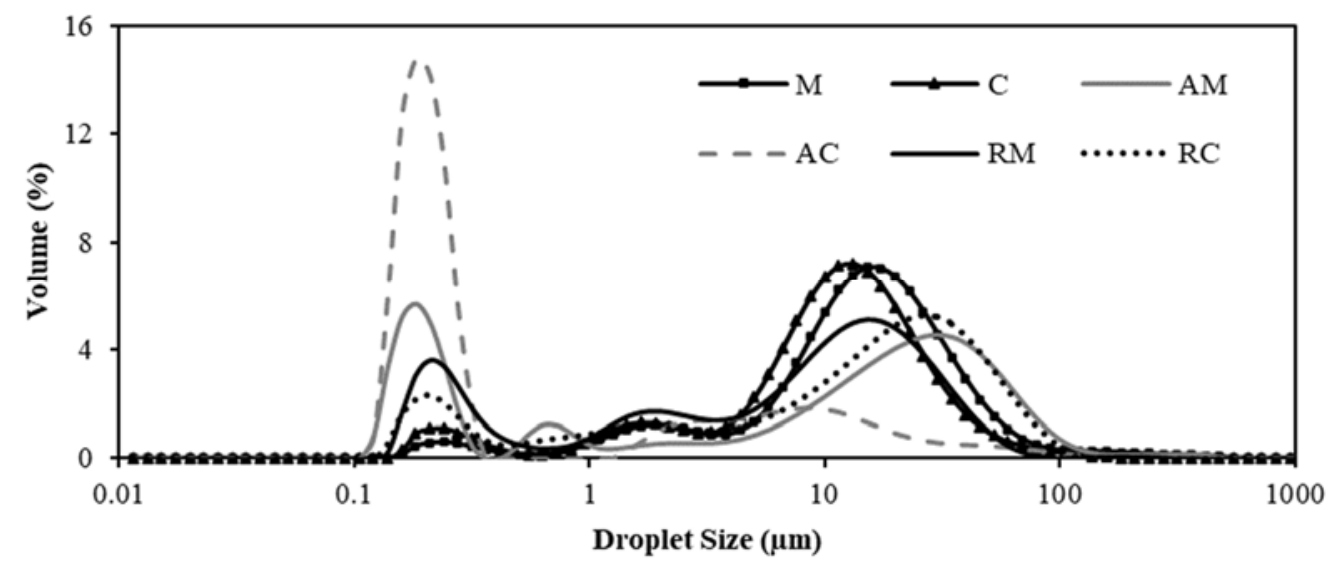

Figure 1. Droplet size distribution of six emulsion prototypes. AC: containing anatase $\mathrm{TiO}_{2}$ with GCO; AM: containing anatase $\mathrm{TiO}_{2}$ with mineral oil; RC: containing rutile $\mathrm{TiO}_{2}$ with GCO; RM: containing rutile $\mathrm{TiO}_{2}$ with mineral oil; $\mathrm{M}$ : control containing the mineral oil; $\mathrm{C}$ : control containing the GCO.

Structure Analysis

(A) Dynamic viscosity-Flow curves

The Figure 2 shows the flow curve of the six emulsions studied. These data show that both anatase and rutile formulations were influenced by the oil type. All formulations could be classified as non-Newtonian fluids with thixotropic hysteresis loops.

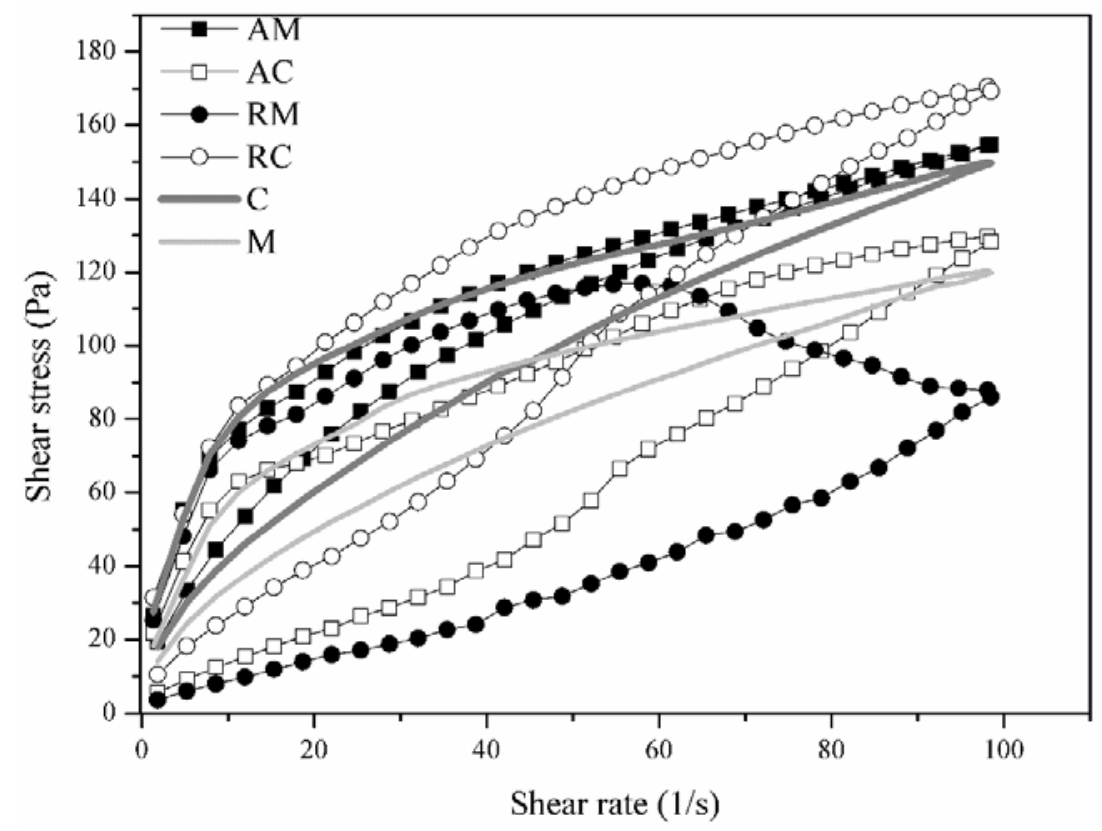

Figure 2. Flow curves of six emulsion prototypes. AC: containing anatase $\mathrm{TiO}_{2}$ with $\mathrm{GCO}$; $\mathrm{AM}$ : containing anatase $\mathrm{TiO}_{2}$ with mineral oil; RC: con-taining rutile $\mathrm{TiO}_{2}$ with $\mathrm{GCO}$; RM: containing rutile $\mathrm{TiO}_{2}$ with mineral oil; $\mathrm{M}$ : control containing the mineral oil; $\mathrm{C}$ : control containing the GCO. 
The influence of $\mathrm{TiO}_{2}$ on viscosity and thixotropic behavior could be verified comparing the prototypes $\mathrm{AC} / \mathrm{AM}$ (anatase $\mathrm{TiO}_{2}$ ) to $\mathrm{RC} / \mathrm{RM}\left(\right.$ rutile $\mathrm{TiO}_{2}$ ). In particular, the anatase form increased the apparent viscosity values at the apex of the curves and rutile increased the thixotropy (especially RM).

The addition of GCO promoted different interactions with rutile and anatase $\mathrm{TiO}_{2}$. When the oil was added to the formulation containing anatase $\mathrm{TiO}_{2}$ (prototype $\mathrm{AC}$ ), the viscosity decreased and on the contrary, the thixotropy increased. This profile was exactly the opposite regarding the formulation containing rutile $\mathrm{TiO}_{2}$ and $\mathrm{GCO}$ (prototype $\mathrm{RC}$ ).

(B) Oscillation measurements

The elastic/storage $\left(\mathrm{G}^{\prime}\right)$ and viscous/loss $\left(\mathrm{G}^{\prime \prime}\right)$ moduli were obtained from the frequency sweep within the linear viscoelastic region (LVR), previously determined from a stress sweep at a frequency of $1 \mathrm{~Hz}$ [18]. The storage modulus $\mathrm{G}^{\prime}$ corresponds to the elastic portion of the viscoelastic behavior, which describes the solid-state of the sample representing the stored deformation energy through internal friction between the constituents in a flowing fluid [17]. The loss modulus G" corresponds to the viscous portion of the viscoelastic behavior, which describes the liquid-state of the sample representing the deformation energy lost through internal friction [34].

In the frequency sweep assay (Figure 3), all formulations exhibited $G^{\prime}$ values higher than $G^{\prime \prime}$ which means that the elastic modulus was predominant and an indicator of high stability of the formulations with strong bonds, both in the presence and absence of GCO.

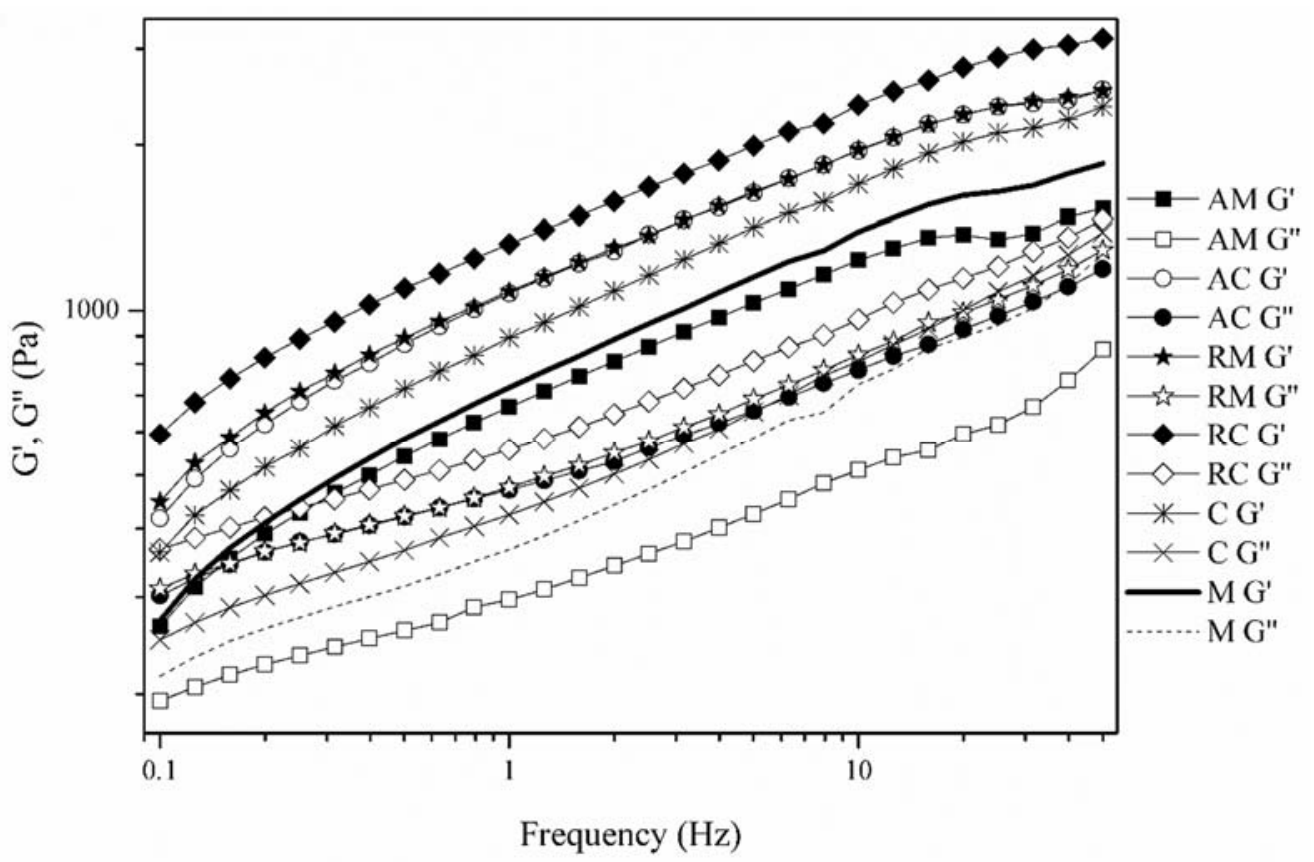

Figure 3. Frequency sweep of six sunscreen prototypes. AC: containing anatase $\mathrm{TiO}_{2}$ with GCO; $\mathrm{AM}$ : containing anatase $\mathrm{TiO}_{2}$ with mineral oil; $\mathrm{RC}$ : containing rutile $\mathrm{TiO}_{2}$ with $\mathrm{GCO}$; $\mathrm{RM}$ : containing rutile $\mathrm{TiO}_{2}$ with mineral oil; $\mathrm{M}$ : control containing the mineral oil; $\mathrm{C}$ : control containing the GCO.

Considering the formulations containing anatase $\mathrm{TiO}_{2}$ in the presence of the green coffee oil (prototype AC), the G' values increased and were higher than $G^{\prime \prime}$ compared to the mineral oil (prototype AM). The same behavior was observed for formulations containing rutile $\mathrm{TiO}_{2}$ (prototypes $\mathrm{RC}$ and $\mathrm{RM}$ ).

The creep and recovery results are shown in Figure 4. All formulations were viscoelastic when they were tested in creep mode and exhibited the same general shape. The overall results show that the total compliances (J) of AM, RM and M were higher than AC, RC and $\mathrm{C}$, respectively, implying that GCO formulations possessed a more delicate network 
than the others. Considering that this behavior is observed in control formulations, the reduction of deformation ability should be attributed to GCO interactions.

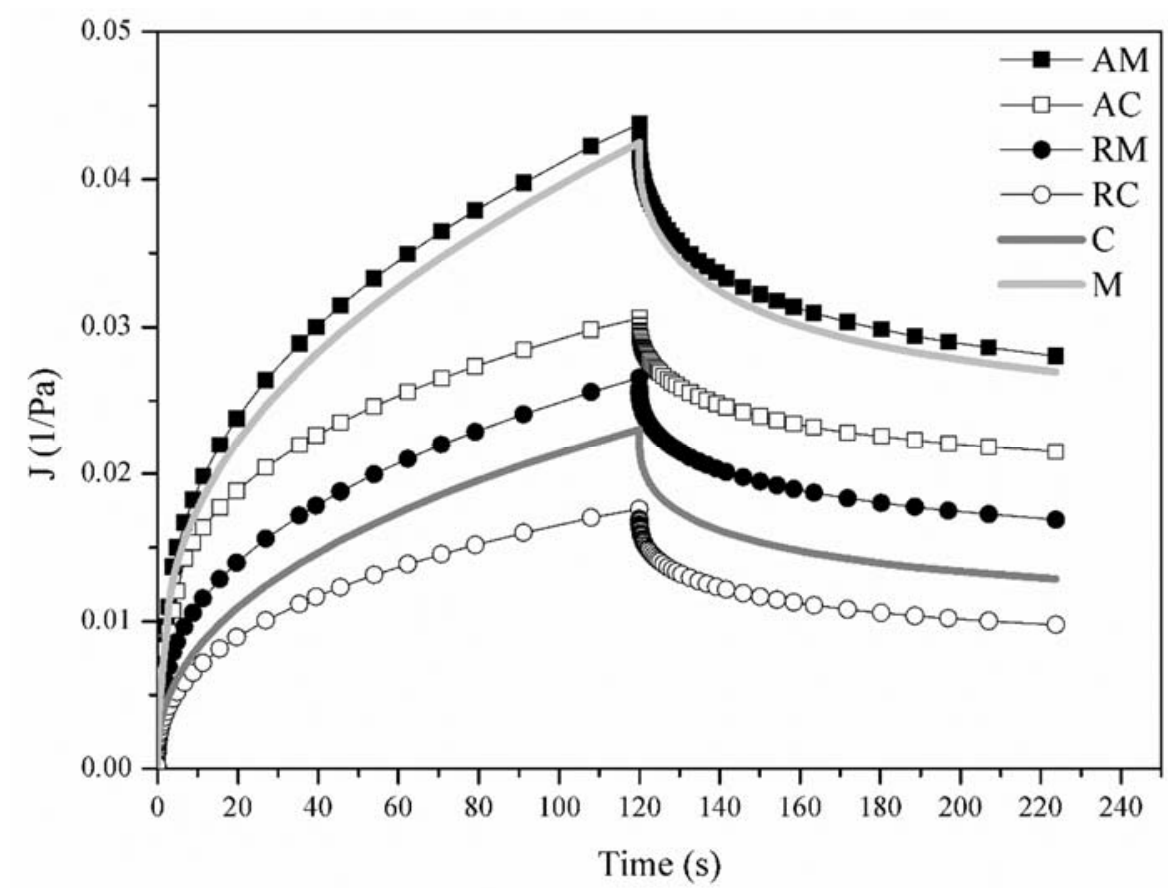

Figure 4. Creep and recovery assay of six sunscreen prototypes. AC: containing anatase $\mathrm{TiO}_{2}$ with GCO; AM: containing anatase $\mathrm{TiO}_{2}$ with mineral oil; $\mathrm{RC}$ : containing rutile $\mathrm{TiO}_{2}$ with GCO; RM: containing rutile $\mathrm{TiO}_{2}$ with mineral oil; $\mathrm{M}$ : control containing the mineral oil; $\mathrm{C}$ : control containing the GCO.

TPA

The mechanical properties studied by TPA clearly depend on the addition of GCO and $\mathrm{TiO}_{2}$, as it can be seen on Table 3 except the cohesiveness that remains similar in all instances.

Table 3. Mechanical properties of six sunscreen prototypes. Results expressed as mean $\pm \mathrm{SD}, n=3$.

\begin{tabular}{|c|c|c|c|c|}
\hline Formulations & $\begin{array}{c}\text { Compressibility } \\
\text { (g.s) }\end{array}$ & Hardness (g) & $\begin{array}{c}\text { Adhesiveness } \\
\text { (g.s) }\end{array}$ & Cohesiveness \\
\hline $\mathrm{AM}$ & $27.84 \pm 0.77$ & $18.47 \pm 1.15$ & $25.95 \pm 2.99$ & $0.74 \pm 0.02$ \\
\hline $\mathrm{AC}$ & $31.53 \pm 2.87$ & $20.38 \pm 1.53$ & $32.19 \pm 3.09^{a}$ & $0.76 \pm 0.02$ \\
\hline $\mathrm{RM}$ & $28.12 \pm 2.50^{a}$ & $18.98 \pm 0.32^{\mathrm{a}}$ & $31.36 \pm 1.15^{\mathrm{c}, \mathrm{e}}$ & $0.76 \pm 0.03$ \\
\hline $\mathrm{RC}$ & $34.45 \pm 2.75^{b}$ & $22.01 \pm 1.05^{b}$ & $36.11 \pm 3.19^{d}$ & $0.73 \pm 0.03$ \\
\hline $\mathrm{M}$ & $24.71 \pm 1.03$ & $16.43 \pm 0.58$ & $20.53 \pm 2.07^{\mathrm{f}}$ & $0.77 \pm 0.02$ \\
\hline $\mathrm{C}$ & $26.81 \pm 1.64^{c}$ & $18.57 \pm 0.87^{c}$ & $24.37 \pm 2.27^{b}$ & $0.77 \pm 0.02$ \\
\hline
\end{tabular}

AC: containing anatase $\mathrm{TiO}_{2}$ with $\mathrm{GCO}$; $\mathrm{AM}$ : containing anatase $\mathrm{TiO}_{2}$ with mineral oil; $\mathrm{RC}$ : containing rutile $\mathrm{TiO}_{2}$ with GCO; RM: containing rutile $\mathrm{TiO}_{2}$ with mineral oil; $\mathrm{M}$ : control containing the mineral oil; $\mathrm{C}$ : control containing the GCO. Different ordered letters represent statistical differences between groups, i.e., between RM and RC; RC and $C$ for Compressibility and Hardness and between $A C$ and C; RM and RC; RM and M for Adhesiveness.

The presence of GCO increases the value of compressibility, hardness and adhesiveness as shown by the comparison of controls. The inclusion of $\mathrm{TiO}_{2}$ points out an increase of these properties, slightly higher for the rutile form (when comparing data from AM, RM and $\mathrm{M}$ formulations). The combination of $\mathrm{GCO}$ plus $\mathrm{TiO}_{2}$ enhances this improvement. 
Considering that adhesiveness is more related to surface characteristics and depends on a combined effect of adhesive and cohesive forces [32,35], it can be considered that the predominance of adhesion forces.

These results also allow the prediction of a higher water resistance for these sunscreen formulations compared to the respective controls.

In Vitro Studies of Sun Protection Factor (SPF) and Water Resistance Retention (WRR)

The Table 4 shows the SPF values and WRR percentage measured for $\mathrm{TiO}_{2}$ formulations.

Table 4. SPF and WRR values of the sunscreen prototypes. Results expressed as mean \pm SD, $n=3$. Different ordered letters represent statistical differences between groups.

\begin{tabular}{ccc}
\hline Formulation & SPF & WRR (\%) \\
\hline AC & $40.37 \pm 3.24^{\mathrm{a}}$ & $42.41 \pm 2.95^{\mathrm{a}}$ \\
AM & $26.08 \pm 1.43^{\mathrm{b}}$ & $59.64 \pm 3.56^{\mathrm{b}}$ \\
RC & $32.4 \pm 1.67^{\mathrm{c}}$ & $76.16 \pm 5.38^{\mathrm{c}}$ \\
RM & $32.4 \pm 1.88^{\mathrm{c}}$ & $88.08 \pm 7.49^{\mathrm{d}}$ \\
\hline
\end{tabular}

AC: containing anatase $\mathrm{TiO}_{2}$ with GCO; AM: containing anatase $\mathrm{TiO}_{2}$ with mineral oil; $\mathrm{RC}$ : containing rutile $\mathrm{TiO}_{2}$ with GCO; RM: containing rutile $\mathrm{TiO}_{2}$ with mineral oil.

Regarding the SPF, the values obtained were superior to 20 , and the highest and lowest values corresponded to anatase $\mathrm{TiO}_{2}$ form with GCO (AC) and mineral oil (AM), respectively. Thus, the oil type clearly influenced this result even though the same did not occur in rutile $\mathrm{TiO}_{2}$ formulations ( $\mathrm{RC}$ and $\mathrm{RM}$ ) which presented the same SPF. The influence of $\mathrm{TiO}_{2}$ form was better evidenced in absence of coffee oil, where rutile $\mathrm{TiO}_{2}(\mathrm{RM})$ was more effective as an $\mathrm{UV}$ attenuator than anatase $\mathrm{TiO}_{2}(\mathrm{AM})$, due to higher refractive index of rutile form. In addition to UV protection conferred by these inorganic filters, it should be also considered the absorbance of UV-B rays by ethylhexyl methoxycinnamate, an organic filter also present in the composition of these prototype formulations.

In addition, another factor that varies the level of protection is the water contact since UV absorbers present in the formulation can leach out or be physically removed by the washing action [24]. It should be noted that in vivo WRR testing of topical sunscreens is expensive, time consuming and experimentally sticky [36] and that was why an in vitro method was here used.

Products which claim to be 'water resistant' exhibit a gradual decrease in protection over the first immersion but lose extraordinarily little protection over the following immersions. In particular, 'water resistant' products should comply with Cosmetics Europe proposed guidelines on water resistance labeling [24]: the 'waterproof' products have a $\%$ WRR exceeding $80 \%$ after two immersions, while the \%WRR of 'water resistant' products is more than $50 \%$. This claim can be sustained for all tested formulations except anatase $\mathrm{TiO}_{2}$ sunscreen with GCO. In fact, rutile $\mathrm{TiO}_{2}$ sunscreens were more water resistant than anatase ones.

Topical Delivery Studies

(A) In vitro caffeine release

Topical delivery studies were only performed in $\mathrm{TiO}_{2}$ sunscreens containing GCO (AC and $\mathrm{RC}$ ) since these were the intended formulations besides the improved outcomes previously obtained in other assays.

The release profiles of caffeine from the $\mathrm{TiO}_{2}$ sunscreens containing $\mathrm{GCO}$ (AC and $\mathrm{RC}$ ) as well as from the control (C) were expressed as percentage of the applied dose and presented in Figure 5.

The profiles were similar for the three types of formulations pointing a global effect of the basis of emulsion. The release of caffeine starts immediately and increases steadily over $6 \mathrm{~h}$, which was considered the standard interval between doses. The analysis of the 
percentage released at this point revealed no statistical differences whereas at $24 \mathrm{~h}$, the amount of control released was higher compared to the other two formulations. This result confirms the ability of $\mathrm{TiO}_{2}$ to adsorb caffeine.

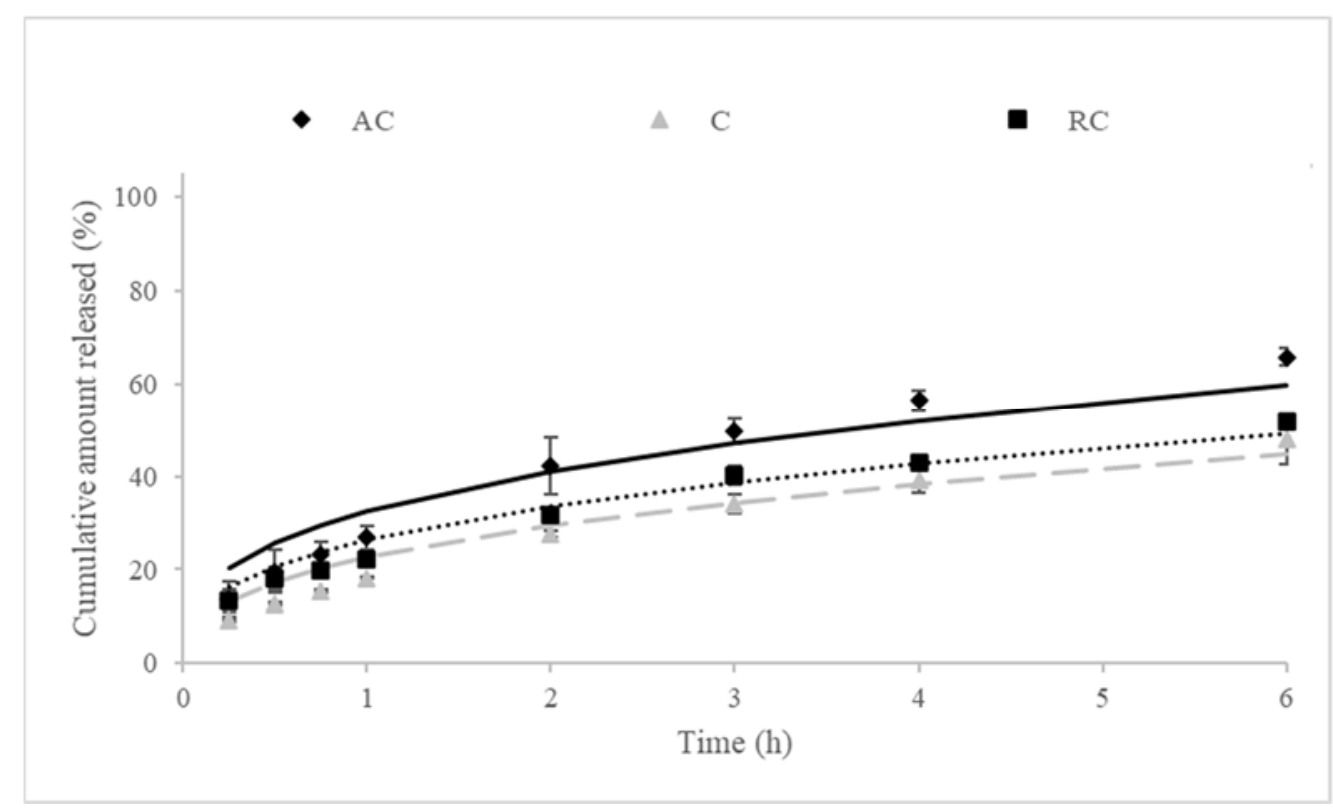

Figure 5. Release profiles of caffeine from formulations containing GCO. Results expressed as mean $\pm \mathrm{SD}, n=6$. AC: containing anatase $\mathrm{TiO}_{2}$ with $\mathrm{GCO}$; $\mathrm{RC}$ : containing rutile $\mathrm{TiO}_{2}$ with $\mathrm{GCO}$; $\mathrm{C}$ : control containing the GCO.

The constant release values (Kd) calculated according to Equation (5) are summarized in Table 5.

Table 5. Release parameters of caffeine from formulations containing GCO. Results expressed as mean $\pm \mathrm{SD}, n=6$. Different ordered letters represent statistical differences between groups.

\begin{tabular}{cccccc}
\hline Formulation & $\mathbf{K d ~}^{\left(\mathbf{h}^{-1}\right)}$ & $\pm \mathbf{S D}$ & $\boldsymbol{n}$ & $\pm \mathbf{S D}$ & $\mathbf{R}^{\mathbf{2}}$ \\
\hline $\mathrm{AC}$ & 30.51 & $\pm 2.67^{\mathrm{a}}$ & 0.31 & \pm 0.03 & 0.9757 \\
\hline $\mathrm{RC}$ & 20.79 & $\pm 0.83^{\mathrm{b}}$ & 0.39 & \pm 0.02 & 0.9931 \\
\hline $\mathrm{C}$ & 25.07 & $\pm 1.43^{\mathrm{c}}$ & 0.33 & \pm 0.02 & 0.9910 \\
\hline
\end{tabular}

$\overline{\mathrm{AC}}$ : containing anatase $\mathrm{TiO}_{2}$ with $\mathrm{GCO}$; $\mathrm{RC}$ : containing rutile $\mathrm{TiO}_{2}$ with $\mathrm{GCO} ; \mathrm{C}$ : control con-taining the $\mathrm{GCO}$.

Taken the n-value into account, the release can be attributed mainly to a passive diffusion process, as the $\mathrm{n}$ values are below 0.5 [37]. The release rate constants show that the presence of anatase $\mathrm{TiO}_{2}$ increases this parameter due to its hydrophilic nature. In contrast, rutile $\mathrm{TiO}_{2}$ can retain the active compound (i.e., caffeine) and decreases the release rate. Considering that the pharmaceutical form of these formulations is an emulsion, this finding implies that this release is obtained by diffusion of the active compound from the aqueous external phase. Thus, the oily internal phase has probably a depot effect, as caffeine is in equilibrium between the two phases. As a sunscreen product, this result is desired since the active is not rapidly released, reducing the possibility of its permeation through the deeper skin layers, as further confirmed.

(B) In vitro caffeine permeability

The $\mathrm{TiO}_{2}$ particles are not expected to diffuse through the intact skin due to their size $(>100 \mathrm{~nm})$. On the contrary, the main active component of the GCO, caffeine, has a well-known ability to diffuse through skin to the deeper layers [38], where it can produce its antioxidant and protective activity. To check if the active compound would reach the 
target tissue, a permeability study using Franz diffusion cells and porcine skin (a widely accepted surrogate for human skin) was conducted. In this case, the GCO (only the oil) and a caffeine solution were also used as controls to compare the permeability profile.

The results are shown in Figure 6. As the permeability of the oil was 30-fold higher than the rest of the formulations, the emulsion creams and the solutions are separately represented.

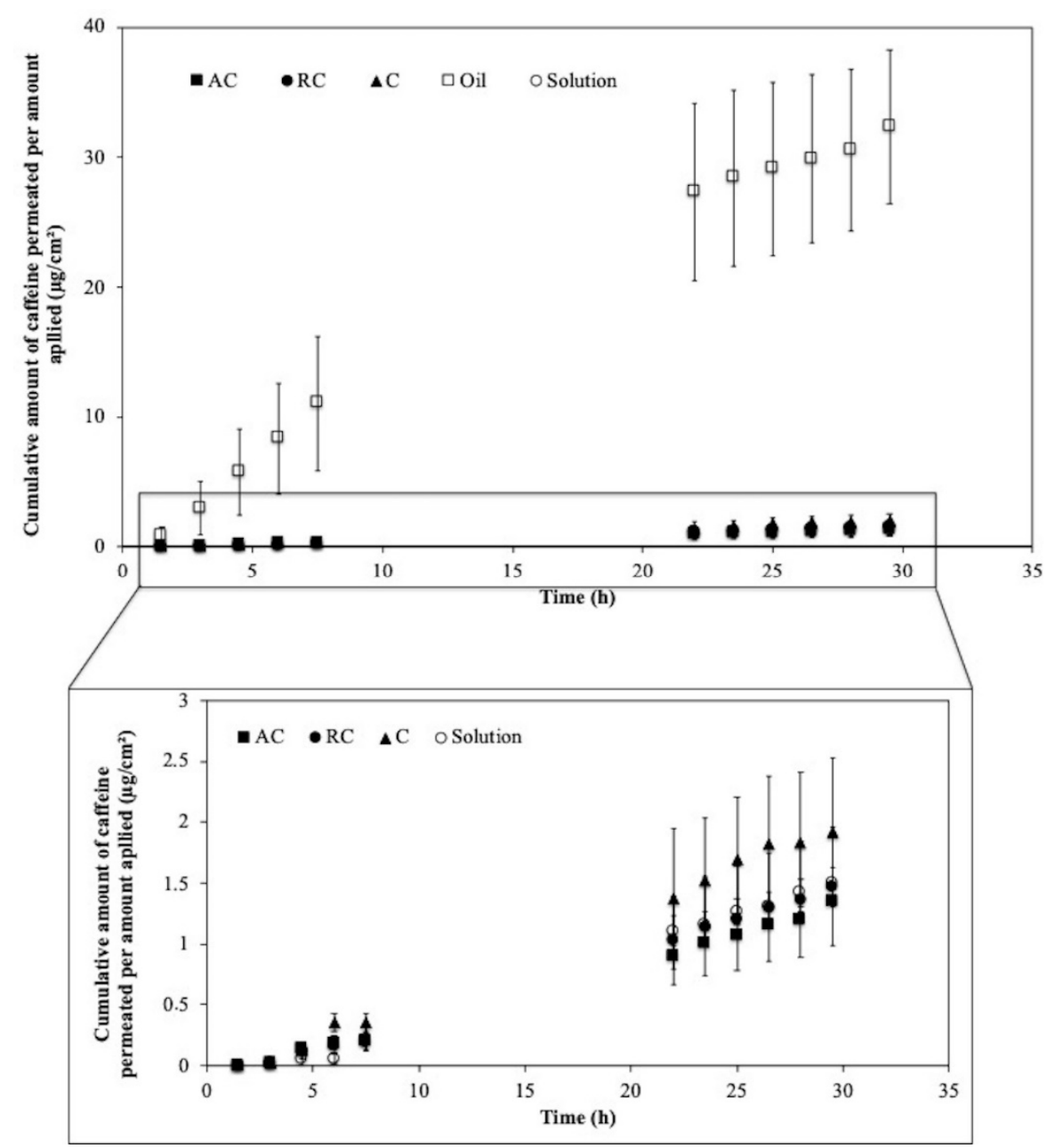

Figure 6. Caffeine permeability assays from the $\mathrm{TiO}_{2}$ sunscreen prototypes (AC and $\mathrm{RC}$ ) and the controls. Results expressed as mean $\pm \mathrm{SD}, n=6$. AC: containing anatase $\mathrm{TiO}_{2}$ with GCO; RC: containing rutile $\mathrm{TiO}_{2}$ with GCO; C: control containing GCO; Oil: Green Coffee Oil (GCO); Solution: Caffeine Solution.

The parameters calculated after applying the linear regression of the values correspondent to the steady state of each curve are summarized in Table 6.

The lag time $\left(t_{L}\right)$ varied between 0.1 to $3.4 \mathrm{~h}$. As the linear regression fitting was inaccurate regarding this parameter, it can be concluded from the obtained results that the steady state was reached quite soon and faster in the emulsion sunscreens than the caffeine solution, even though slower than the green coffee oil (GCO). The occlusive effect of the oil, the higher caffeine content, and the presence of an oily medium, that could somehow interact with the lipids of the stratum corneum lipid matrix could be responsible for this effect. In fact, several fatty acids present in oils (including this one) have been reported as permeability enhancers, such as oleic acid [37]. 
Table 6. Parameters defining the transdermal permeability of caffeine from the $\mathrm{TiO}_{2}$ sunscreen prototypes (AC, RC) and the controls (C, GCO and caffeine solution). Results expressed as mean \pm $\mathrm{SD}, n=6$.

\begin{tabular}{ccccc}
\hline Formulation & $\boldsymbol{J}\left(\mathbf{\%} / \mathbf{c m}^{\mathbf{2}} \mathbf{h}\right)$ & $\boldsymbol{t}_{\mathbf{L}}(\mathbf{h})$ & $\mathbf{R}^{2}$ & $\boldsymbol{K} \mathbf{~} \mathbf{c m} / \mathbf{s})$ \\
\hline $\mathrm{AC}$ & $0.05 \pm 0.02$ & $1.96 \pm 0.86$ & $0.996 \pm 0.002$ & $4.79 \times 10^{-07} \pm 1.90 \times 10^{-07}$ \\
\hline $\mathrm{RC}$ & $0.05 \pm 0.02$ & $2.36 \pm 1.34$ & $0.997 \pm 0.003$ & $5.83 \times 10^{-07} \pm 2.03 \times 10^{-07}$ \\
\hline $\mathrm{C}$ & $0.07 \pm 0.02$ & $1.90 \pm 0.35$ & $0.989 \pm 0.011$ & $7.76 \times 10^{-07} \pm 2.60 \times 10^{-07}$ \\
\hline GCO (Oil) & $1.20 \pm 0.28^{*}$ & $0.08 \pm 1.16$ & $0.988 \pm 0.013$ & $3.33 \times 10^{-07} \pm 7.65 \times 10^{-08 *}$ \\
\hline Caffeine Solution & $0.06 \pm 0.01$ & $3.36 \pm 0.73$ & $0.993 \pm 0.003$ & $6.41 \times 10^{-07} \pm 6.95 \times 10^{-08}$ \\
\hline
\end{tabular}

AC: containing anatase $\mathrm{TiO} 2$ with $\mathrm{GCO}$; $\mathrm{RC}$ : containing rutile $\mathrm{TiO} 2$ with $\mathrm{GCO}$; $\mathrm{C}$ : control containing $\mathrm{GCO}$; J: flux $t_{\mathrm{L}}$ : lag time; Kp: permeability coefficient. ${ }^{*}$ Statistically significant differences.

The permeability coefficient $(K p)$ is usually estimated at the steady state, when the drug is concentrated near the saturation range dividing the flux by the drug concentration in the donor compartment [39]. Even though the flux $(J)$ is the parameter that directly shows the access of drug to the lower compartment, the Kp allows a direct comparison between formulations, as this value considers the possible differences between the applied doses.

Considering the $K p$ values, the most efficient formulation was the control $\mathrm{C}$, followed by the caffeine solution, $\mathrm{RC}, \mathrm{AC}$ and then, the GCO, without statistical significance. It might be possible that some ingredients from the emulsion formulations (e.g., propylene glycol or even the surfactants) could act as permeability enhancers of caffeine through the skin, overlapping the expected retarding effect due to the increased viscosity of emulsion prototypes compared to the solution [37]. In addition, no significant differences in skin permeability were observed between rutile and anatase $\mathrm{TiO}_{2}$ sunscreen formulations. Up to our knowledge, no data concerning the influence of $\mathrm{TiO}_{2}$ on the skin permeability has been published to state that rutile or anatase forms could influence the permeability of caffeine.

As it can be observed from these results, GCO showed the highest flux $(J)$. This fact was expected considering that it was the most occlusive formulation (only oil) besides containing the highest concentration of caffeine. However, when the fluxes were normalized with the active concentration in the donor samples, the permeability of caffeine was more efficient, as the permeability coefficient of caffeine solution to the aqueous medium was practically twice than the GCO one $(p<0.05)$. This effect could be due to the higher bioavailability of the drug when dissolved in an aqueous solution as well as to the depot effect of the GCO in caffeine permeability. At least, no significant differences between the flux values were obtained when comparing both $\mathrm{TiO}_{2}$ sunscreen formulations among each other and the other caffeine controls.

\section{Conclusions}

Hereby, a successful design of several emulsion prototype sunscreen formulations containing anatase or rutile $\mathrm{TiO}_{2}$ particles and a natural oil extract, rich in caffeine (GCO) has been clearly demonstrated. Both $\mathrm{TiO}_{2}$ forms combined with GCO provided suitable rheological properties, particle size, SPF and WRR and caffeine release, and thus, an effective UV-light protection. Future studies will be performed in another project to fully characterize the oily extract from coffee beans to deeply understand the mechanism of action (besides caffeine) behind this UV-light protection.

Author Contributions: The manuscript was written through contributions of all authors. All authors have given approval to the final version of the manuscript. V.I., H.M.R. and T.M.G. have supervised this work.

Funding: This research was funded by Coordenação de Aperfeiçoamento de Pessoal de Nível Superior-CAPES (Código de financiamento 001); FINEP; PADC-FCF-UNESP; Fundação para a Ciência e Tecnologia (Portugal, UID/DTP/04138/2019); Conselleria d'Educacio, Cultura i Esport of 
Generalitat Valenciana (Proyecto Emergente GV2015-054). University of Valencia, acciones especiales de investigación 2019.

Institutional Review Board Statement: The Ethical Committee approval of the University of Valencia was obtained under the protocol number H1462978691586.

Conflicts of Interest: The authors declare no conflict of interest.

\section{References}

1. Svobodová, A.R.; Galandakova, A.; Šianská, J.; Doležal, D.; Lichnovská, R.; Ulrichova, J.; Vostálová, J. DNA damage after acute exposure of mice skin to physiological doses of UVB and UVA light. Arch. Dermatol. Res. 2012, 304, 407-412. [CrossRef]

2. Mancuso, J.B.; Maruthi, R.; Wang, S.Q.; Lim, H.W. Sunscreens: An update. Am. J. Clin. Dermatol. 2017, 18, 643-650. [CrossRef]

3. Latha, M.S.; Martis, J.; Shobha, V.R.; Shinde, S.; Bangera, S.; Krishnankutty, B.; Bellary, S.; Varughese, P.R.; Naveen Kumar, B.R. Sunscreening agents: A review. J. Clin. Aesthet. Dermatol. 2013, 6, 16-26. [PubMed]

4. Shi, H.; Magaye, R.; Castranova, V.; Zhao, J. Titanium dioxide nanoparticles: A review of current toxicological data. Part. Fibre Toxicol. 2013, 10, 15. [CrossRef]

5. Smijs, T.G.; Pavel, S. Titanium dioxide and zinc oxide nanoparticles in sunscreens: Focus on their safety and effectiveness. Nanotechnol. Sci. Appl. 2011, 4, 95-112. [CrossRef]

6. Zhang, X.; Li, W.; Yang, Z. Toxicology of nanosized titanium dioxide: An update. Arch. Toxicol. 2015, 89, 2207-2217. [CrossRef]

7. Chen, X.X.; Cheng, B.; Yang, Y.X.; Cao, A.; Liu, J.H.; Du, L.J.; Liu, Y.; Zhao, Y.; Wang, H. Characterization and preliminary toxicity assay of nano-titanium dioxide additive in sugar-coated chewing gum. Small 2013, 9, 1765-1774. [CrossRef]

8. Liu, K.; Lin, X.; Zhao, J. Toxic effects of the interaction of titanium dioxide nanoparticles with chemicals or physi-cal factors. Int. J. Nanomed. 2013, 8, 2509-2520.

9. Yang, H.G.; Sun, C.H.; Qiao, S.Z.; Zou, J.; Liu, G.; Smith, S.C.; Cheng, H.M.; Lu, G.Q. Anatase TiO 2 single crystals with a large percentage of reactive facets. Nature 2008, 453, 638-641. [CrossRef]

10. Vandebriel, R.J.; Vermeulen, J.P.; Van Engelen, L.B.; De Jong, B.; Verhagen, L.M.; De La Fonteyne-Blankestijn, L.J.; Hoonakker, M.E.; De Jong, W.H. The crystal structure of titanium dioxide nanoparticles influences immune activity in vitro and in vivo. Part. Fibre Toxicol. 2018, 15, 9. [CrossRef]

11. Yeh, M.-I.; Huang, H.-C.; Liaw, J.-H.; Huang, M.-C.; Huang, K.-F.; Hsu, F.-L. Dermal delivery by niosomes of black tea extract as a sunscreen agent. Int. J. Dermatol. 2013, 52, 239-245. [CrossRef]

12. Chiari-Andréo, B.G.; Trovatti, E.; Pecoraro, É.; Corrêa, M.A.; Cicarelli, R.M.B.; Ribeiro, S.J.L.; Isaac, V.L.B. Synergistic effect of green coffee oil and synthetic sunscreen for health care application. Ind. Crop. Prod. 2014, 52, 389-393. [CrossRef]

13. Marto, J.; Gouveia, L.; Chiari-Andréo, B.G.; Paiva, A.; Isaac, V.; Pinto, P.; Simões, P.; Almeida, A.; Ribeiro, H. The green generation of sunscreens: Using coffee industrial sub-products. Ind. Crop. Prod. 2016, 80, 93-100. [CrossRef]

14. Rosado, C.; Tokunaga, V.K.; Sauce, R.; De Oliveira, C.A.; Sarruf, F.D.; Filho, R.P.; Maurício, E.; De Almeida, T.S.; Velasco, M.V.R.; Baby, A.R. Another reason for using caffeine in dermocosmetics: Sunscreen adjuvant. Front. Physiol. 2019, 10, 519. [CrossRef] [PubMed]

15. Kawasumi, M.; Lemos, B.; Bradner, J.E.; Thibodeau, R.; Kim, Y.-S.; Schmidt, M.; Higgins, E.; Koo, S.-W.; Angle-Zahn, A.; Chen, A.; et al. Protection from UV-induced skin carcinogenesis by genetic inhibition of the ataxia telangiectasia and Rad3-related (ATR) kinase. Proc. Natl. Acad. Sci. USA 2011, 108, 13716-13721. [CrossRef] [PubMed]

16. Chen, L.; Hu, J.Y.; Wang, S.Q. The role of antioxidants in photoprotection: A critical review. J. Am. Acad. Dermatol. 2012, 67, 1013-1024. [CrossRef]

17. Isaac, V.L.B.; Moraes, J.D.D.; Chiari-Andréo, B.G.; Guglielmi, D.A.S.; Cefali, L.C.; Rissi, N.C.; Corrêa, M.A. Determination of the real influence of the addition of four thickening agents in creams using rheological measurements. J. Dispers. Sci. Technol. 2013, 34, 532-538. [CrossRef]

18. Isaac, V.L.B.; Chiari-Andréo, B.G.; Marto, J.M.; Moraes, J.D.D.; Leone, B.A.; Corrêa, M.A.; Ribeiro, H.M. Rheology as a tool to predict the release of alpha-lipoic acid from emulsions used for the prevention of skin aging. BioMed Res. Int. 2015, 2015, 1-8. [CrossRef] [PubMed]

19. Silva, S.; Pinto, F.V.; Antunes, F.; Miguel, M.G.; Sousa, J.; Pais, A. Aggregation and gelation in hydroxypropylmethyl cellulose aqueous solutions. J. Colloid Interface Sci. 2008, 327, 333-340. [CrossRef]

20. Vitorino, C.; Alves, L.; Antunes, F.; Sousa, J.; Pais, A.A.C.C. Design of a dual nanostructured lipid carrier formulation based on physicochemical, rheological, and mechanical properties. J. Nanoparticle Res. 2013, 15, 1-14. [CrossRef]

21. Chiari, B.G.; Almeida, M.G.J.; Corrêa, M.A.; Isaac, V. Cosmetics' quality control. In Latest Research into Quality Control; Akyar, I., Ed.; TechOpen: London, UK, 2012; pp. 337-364.

22. European Medicines Agency. Guideline on Bioanalytical Method Validation. EMA Guideline. 2012. Available online: https: //www.ema.europa.eu/en/documents/scientific-guideline/guideline-bioanalytical-method-validation_en.pdf (accessed on 31 December 2019).

23. Kale, S.; Ghoge, P.; Ansari, A.; Waje, A. Formulation and in-vitro determination of sun protection factor of Ni-gella sativa Linn. seed oil sunscreen cream. Int. J. Pharm. Tech. Res. 2010, 2, 2194-2197. 
24. Cosmetics Europe. $N^{\circ}$ 16: WATER RESISTANCE LABELLING. 2005. Available online: https://www.cosmeticseurope.eu/files/ 2114/6408/3694/CR_16_Water.pdf (accessed on 31 December 2019).

25. Ahn, S.; Yang, H.; Lee, H.; Moon, S.; Chang, I. Alternative evaluation method in vitro for the water-resistant ef-fect of sunscreen products. Skin Res. Technol. 2008, 14, 187-191. [CrossRef] [PubMed]

26. OECD. Test No. 428: Skin Absorption. In Vitro Method; OECD Publishing: Paris, France; Available online: https://www.oecdilibrary.org/environment/test-no-428-skin-absorption-in-vitro-method_9789264071087-en (accessed on 31 December 2019).

27. Srdjenovic, B.; Djordjevic-Milic, V.; Grujic, N.; Injac, R.; Lepojevic, Z. Simultaneous HPLC determination of caf-feine, theobromine, and theophylline in food, drinks, and herbal products. J. Chromat. Sci. 2008, 46, 144-149. [CrossRef]

28. Bhawani, S.A.; Fong, S.S.; Ibrahim, M.N.M. Spectrophotometric analysis of caffeine. Int. J. Anal. Chem. 2015, 2015, 1-7. [CrossRef]

29. Ritger, P.L.; Peppas, N.A. A simple equation for description of solute release I. Fickian and non-fickian release from non-swellable devices in the form of slabs, spheres, cylinders or discs. J. Control. Release 1987, 5, 23-36. [CrossRef]

30. Wang, S.Q.; Tooley, I.R. Photoprotection in the era of nanotechnology. Semin. Cutan. Med. Surg. 2011, 30, 210-213. [CrossRef] [PubMed]

31. European Comission, SCCS. Scientific Committee on Consumer Safety OPINION ON Titanium Dioxide (nano form) coated with Cetyl Phosphate, Manganese Dioxide or Triethoxycaprylylsilane as UV-Filter in Dermally Applied Cosmetic. 2018. Available online: https:/ / ec.europa.eu/health/sites/health/files/scientific_committees/consumer_safety/docs/sccs_o_202.pdf (accessed on 31 December 2019).

32. Marto, J.; Gouveia, L.F.; Gonçalves, L.; Chiari-Andréo, B.G.; Isaac, V.; Pinto, P.; Oliveira, E.; Almeida, A.J.; Ribeiro, H.M. Design of novel starch-based Pickering emulsions as platforms for skin photoprotection. J. Photochem. Photobiol. B 2016, 162, 56-64. [CrossRef] [PubMed]

33. Ohno, T.; Sarukawa, K.; Tokieda, K.; Matsumura, M. Morphology of a $\mathrm{TiO}_{2}$ photocatalyst (Degussa, P-25) con-sisting of anatase and rutile crystalline phases. J. Catalys. 2001, 203, 82-86. [CrossRef]

34. Lee, J.C.; Porcar, L.; Rogers, S.A. Unveiling temporal nonlinear structure-rheology relationships under dynamic shearing. Polymers 2019, 11, 1189. [CrossRef] [PubMed]

35. Marto, J.; Ascenso, A.; Gonçalves, L.M.; Gouveia, L.F.; Manteigas, P.; Pinto, P.; Oliveira, E.; Almeida, A.J.; Ribeiro, H.M. Melatonin-based pickering emulsion for skin's photoprotection. Drug Deliv. 2016, 23, 1594-1607. [CrossRef]

36. Melero, A.; Garrigues, T.M.; Alós, M.; Kostka, K.; Lehr, C.-M.; Schaefer, U. Nortriptyline for smoking cessation: Release and human skin diffusion from patches. Int. J. Pharm. 2009, 378, 101-107. [CrossRef]

37. Stokes, R.; Diffey, B.; Dawson, L.; Barton, S. A novel in vitro technique for measuring the water resistance of sunscreens. Int. J. Cosmet. Sci. 1998, 20, 235-240. [CrossRef]

38. Ascenso, A.; Batista, C.; Cardoso, P.; Mendes, T.; Praça, F.; Bentley, M.V.; Raposo, S.; Simões, S. Development, characterization, and skin delivery studies of related ultradeformable vesicles: Transfersomes, ethosomes, and transethosomes. Int. J. Nanomed. 2015, 10, 5837-5851. [CrossRef]

39. Mitragotri, S.; Anissimov, Y.G.; Bunge, A.L.; Frasch, H.F.; Guy, R.H.; Hadgraft, J.; Kasting, G.B.; Lane, M.E.; Roberts, M.S. Mathematical models of skin permeability: An overview. Int. J. Pharm. 2011, 418, 115-129. [CrossRef] 